\title{
Aging related responses to conflicting proprioceptive and visual information about initial position during reaching
}

\author{
Leia Bernardi Bagesteiro*
}

Abstract Introduction: The purpose of the current study was to examine whether age-related differences are exhibited in the relative contributions of vision and proprioception with initial hand position to the control of movement distance of single-joint reaching movements. Methods: We use a virtual reality display to systematically change the relationship between the actual hand position and the displayed hand position (virtual position) as subjects' positioned a cursor within a start circle. Visual feedback of the reaching hand was only available before movement onset. Two groups of subjects (older and young) reached to two different visual targets $\left(115^{\circ}\right.$ and $125^{\circ}$ elbow angle) from four possible starting locations $\left(90^{\circ}, 95^{\circ}, 100^{\circ}, 105^{\circ}\right.$ elbow angle) under four virtual/actual dissociation conditions $\left(0^{\circ}, 5^{\circ}, 10^{\circ}, 15^{\circ}\right)$. Results: For the mismatched conditions movement distance was generally longer for the older adults as compared to the younger. Also, the younger group better scaled their movement extent with cursor initial location, whereas, the older group showed scaling with hand location. Our results indicate age-related differences in the effects of initial position information when vision and proprioception initial information were dissociated. Conclusion: The young were able to completely rely on visual information through feedforward mechanism applying acceleration amplitude manipulation for controlling movement distance. In contrast, older subjects relied on proprioceptive information for the scaling of peak velocity with movement distance, suggesting more reliance on feedback-mediated errorcorrection mechanisms during the course of movement.

Keywords Aging, Reaching, Distance control, Role of proprioception, Role of vision. 


\section{Introduction}

Aging has been shown to produce deficiencies in both musculoskeletal and neurophysiological functions associated with movement control and coordination. For example, age related reductions in muscle mass (Larsson et al., 1979; Schultz et al., 1992), force production (Cole, 1991; Lanza et al., 2003), and nerve conduction velocity (Rivner et al., 2001; Verdu et al., 2000) have been well documented. However, the degree to which these peripheral changes can account for age-related declines in movement coordination (Falconer et al., 1991), and increases in movement variability (Cooke et al., 1989; Ketcham et al., 2004; Pohl et al., 1996) remain controversial. Previous studies have indicated that the controlling of arm movements in the elderly relies more on online visual feedback of hand position compared to young adults, allowing older adults to compensate for planning deficiencies (Goggin and Meeuwsen, 1992; Haaland et al., 1993; Lyons et al., 1996; Seidler et al., 2002). Conversely, some studies have indicated that the corrective mechanisms related to visual feedback of hand position might become less efficient with age (Chaput and Proteau, 1996b; Serrien et al., 1996). Also, the effects of adult aging on visually mediated feedback and online processes have been well established as well as their increase with task complexity (Ketcham et al., 2002; Light and Spirduso 1990; Salthouse 2000; Sarlegna 2006; Yan et al., 2000). Previous work has documented that cognitive (Raz et al., 2007; Raz and Rodrigue, 2006) and sensorimotor (Verhaeghen et al., 2006) functions gradually decline with advancing age, which has been attributed to a selective shrinkage of the prefrontal cortex (Raz et al., 2005), suggesting age-related deficits on strategy control.

An effective method of distinguishing the role of central processing in motor control is to examine the contributions of sensory information to movement coordination. For example, with regard to aging, studies of upper limb tapping and reaching movements have suggested that deficits in feedforward use of sensory information plays a major role in the slowing of agerelated movement (Cooke et al., 1989; Pohl et al., 1996) and consistent with studies indicating that the elderly rely more on slower feedback processes (Goggin and Meeuwsen, 1992; Haaland et al., 1993; Skinner et al., 1984). Additionally, elderly subjects rely more on visual control when acquiring and performing a precision locomotor task (van Hedel and Dietz, 2004), also showing an increased dependency on vision, when experiencing reduced or conflicting sensory inputs (Teasdale et al., 1991; Woollacott et al., 1986). These results are suggested to be due to an impaired function of proprioceptive feedback mechanisms at higher ages, which can replace visual information in younger subjects (Dietz and Colombo, 1998). However, such abnormalities have not yet been specified, in the centrally generated motor program or as a result of peripheral updating via proprioceptive and visual feedback mechanisms. These studies suggest that while young adults rely on feedforward processes to achieve the goal of speed and accuracy in movement, the elderly tend to rely more on feedback mediated corrective processes.

Serrien et al. (1996) examined the reliance on vision by using visual and proprioceptive sensory conditions during the performance of a bimanual coordination task. Their results demonstrated that the manipulation of proprioceptive input and the absence or presence of visual feedback affected more the young subjects as compared to the elderly group, suggesting that this is related to a reduced sensory sensitivity as a function of aging. The execution of skilled movement relies on vision as the leading sensory modality, although it is assumed that vision and proprioception are strongly linked in the control of movement. Their mutual integration occurs naturally, and the relative contribution of both sources, it is argued, changes throughout development and learning, which could be modified as a function of aging (Allison et al., 2006; Dijkerman and de Haan 2007; Sober and Sabes 2003; Speers et al., 2002). Postural and gait studies support these findings suggesting that aging appears to affect the ability to adjust to alterations in sensory information contributing to impaired postural stability and lateral balance, which results in compensations and sensory reintegration in older adults (Dean et al., 2007; Westlake and Culham, 2007). Postural stability and control of body sway are achieved, in part, through input from the proprioceptive, visual, and vestibular systems. Previous research has shown adapted postural control strategy and postural instability (i.e. increased body sway) to be associated with altered proprioceptive sensitivity and diminished dynamic regulation of sensorimotor integration in older individuals (Brumagne et al., 2004; Peterka and Loughlin 2004).

Some of the literature previously mentioned suggested that aging affects proprioceptive function. As a result, older adults tend to rely more on visual feedback to plan and control movements. Moreover, this decline in motor coordination has been shown in adults as young as 60-65 age range, a range not previously thought of as affected by motor changes. Here we directly tested this hypothesis to verify whether the distortion of sensory information showed different effects in older subjects as compared to the young, suggesting that aging changes the ability 
to use different types of sensory feedback used to control the arm during targeted movements. Based on earlier research in younger adults demonstrating substantial differences in the contributions of visual and proprioceptive information to specification and control of reaching movements (Bagesteiro and Sainburg 2005; Bagesteiro et al., 2006; Sainburg et al., 2003; Sober and Sabes, 2005, 2003). These studies have established that vision and proprioception play differently but complimentary roles in specifying and executing movements; suggesting that the dynamic transformation occurs downstream to kinematic planning in the movement preparation process. Thus, we hypothesized that aging will differentially diminish the role of vision in feedfoward control, as reflected by characteristic features of hand movement. In this study, we used a virtual reality display to dissociate visual and proprioceptive information of limb position prior to targeted single-joint movements. Motions were made at 2 different visual targets, from 4 different start locations, and under 4 virtual/actual dissociation conditions. We were, thus, able to directly assess how subjects from different age groups adjust their movement characteristics, given a discrepancy between visual (cursor) and proprioceptive (hand) information on start location. By analyzing the differences between the cursor/hand alignment information on specific features of the movements (movement distance, acceleration duration, peak tangential hand velocity and peak tangential hand acceleration) we were able to understand the extent to which adjustments in these parameters occur with aging.

\section{Methods}

\section{Participants}

Two groups of unpaid individuals participated in the experiment. The first group included eight young healthy aged 20-33 year olds (four females, four males). The second group consisted of ten older adults with 65-77 years (five females, five males). All participants were right-handed, as indicated by laterality scores (younger group $=91 \%$, older group $=93 \%$ ) on a 34-item modified version of the Edinburgh Inventory (Oldfield, 1971), and were naïve to the purpose of the experiment. Young participants were recruited from the university community. Older participants were recruited from the general community nearby the laboratory; they traveled independently to and from the laboratory for the testing session. All subjects had normal visual acuity (uncorrected or corrected with lenses). Table 1 summarizes the characteristics of each subject group. A brief explanation of the experiment was given to all volunteers and a signed consent form was acquired in accordance with human subject policies.

\section{Experimental procedure}

The experimental procedure of the current study was identical to that of our previous study (Bagesteiro et al., 2006). The experiment consisted of two sessions: practice (30 trials under veridical conditions) to familiarize with the requirements of the task, and 320 repetitive elbow joint extension movements toward one of two targets positioned $25^{\circ}$ and $35^{\circ}$ from the start location. Prior to movement, a start circle and one of two target circles were displayed (approximately distance: Target $0=14 \mathrm{~cm}$; Target $1=20 \mathrm{~cm}$ ). A cursor, providing veridical feedback about the hand point, was to be positioned in the start circle $(1 \mathrm{~cm}$ diameter) for $300 \mathrm{~ms}$. At the presentation of an audiovisual "go" signal, the cursor was blanked. Subjects were instructed to move the hand to the target using a "single, uncorrected, rapid motion". Between trials, cursor feedback was only provided when the hand was within a $3 \mathrm{~cm}$ radius of the center of the start circle. This was done to prevent adaptation to altered visual feedback. Within the 320 trials, 32 different conditions (i.e. (2 targets) $x$ (4 hand locations) $\mathrm{x}$ (4 cursor locations) - as shown in Figure 1A) were interspersed in a pseudorandomly manner. The design of this study produced 10 trials for each of the conditions tested. Subjects had no prior information about the mismatched positions. Figure 1B illustrates the relationship of the subjects' hand to the cursor during the 3 conditions tested: (1) veridical; (2) vision displaced; (3) hand displaced.

Figure 1C illustrates the experimental setup. Subjects sat facing a projection screen with either the right or left arm supported over a horizontal table top, positioned just below shoulder height (adjusted to subjects' comfort), by an air-jet system, which reduces the effects of gravity and friction. A cursor representing finger position, a start circle, and a target were projected on a horizontal back-projection screen

Table 1. Summary of participants' information.

\begin{tabular}{lcc}
\hline $\begin{array}{c}\text { Variable } \\
(\text { mean } \pm \text { SD) }\end{array}$ & Young & Elder \\
\hline $\mathrm{N}$ & 8 & 10 \\
Age (years) & $24.6 \pm 5.3$ & $69.6 \pm 5.2$ \\
Weight $(\mathrm{kg})$ & $63.8 \pm 7.7$ & $69.8 \pm 13.2$ \\
Height $(\mathrm{m})$ & $1.73 \pm 0.08$ & $1.59 \pm 0.08$ \\
MMSE score & $29.3 \pm 0.6$ & $28.8 \pm 0.6$ \\
Education (years) & $15.4 \pm 2.1$ & $14.8 \pm 3.5$ \\
Left hand grip (N) & $323 \pm 21$ & $297 \pm 11$ \\
Right hand grip (N) & $378 \pm 18$ & $336 \pm 15$ \\
\hline
\end{tabular}


positioned above the arm. A mirror, positioned parallel and below this screen, reflected the visual display, so as to give the illusion that the display was in the same horizontal plane as the fingertip (virtual image). Calibration of the display assured that this projection was veridical. All joints distal to the elbow were immobilized using an adjustable brace. This virtual reality environment assured that subjects had no visual feedback of their arm during an experimental session. Movements of the trunk and scapula were restricted using a butterfly-shaped chest restraint. Position and orientation of the segments, proximal and distal, of

A

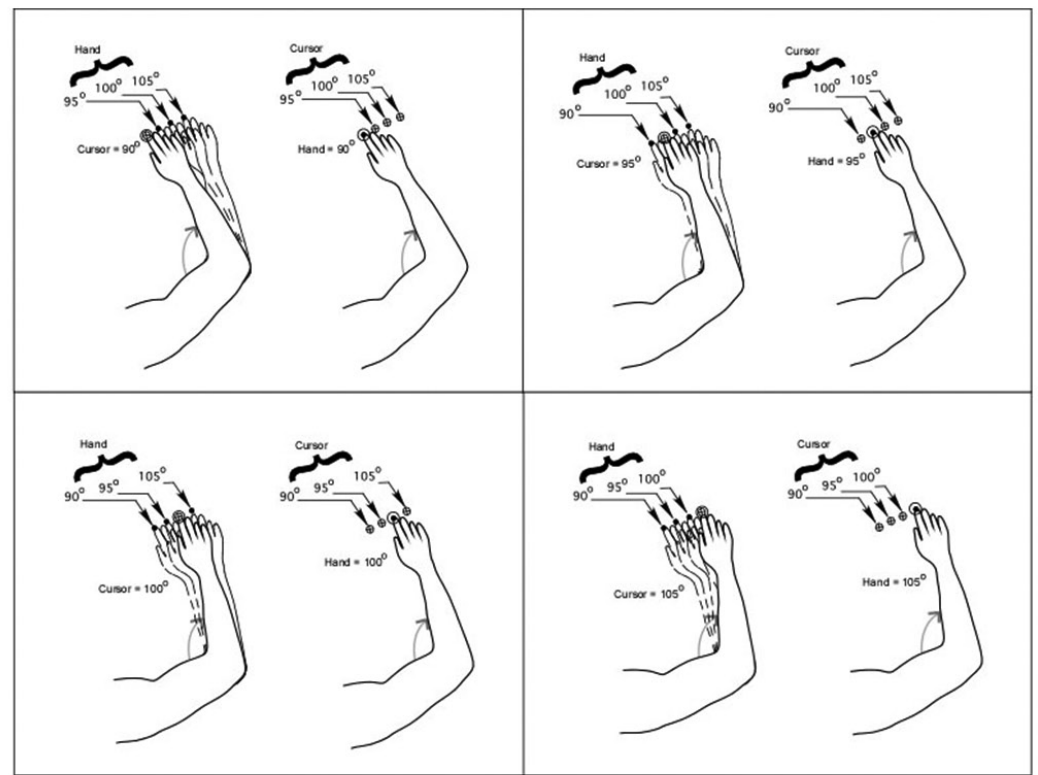

B

(1) Veridica (Target

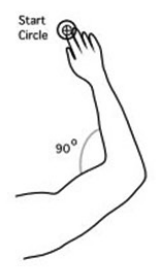

(2) Vision displaced

$$
\text { (O) Target }
$$

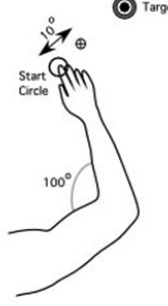

(3) Hand displaced

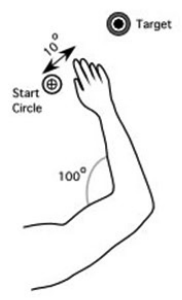

C
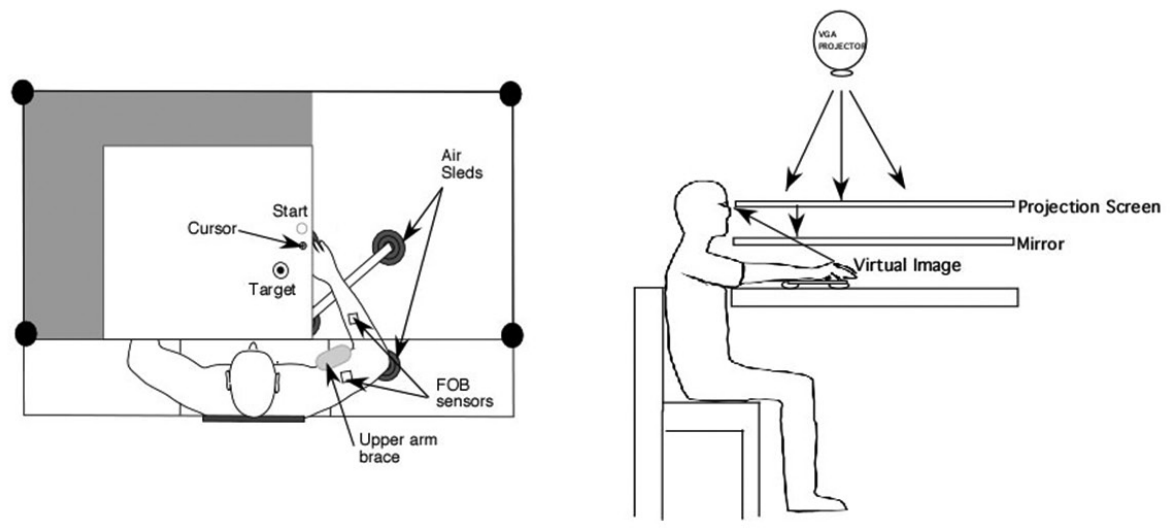

Figure 1. (A) Possible hand start locations (90, 95, 100, and $105^{\circ}$ elbow angle) and visual cursor start location conditions (difference between virtual and actual elbow angle: $0,5,10$, and $15^{\circ}$ ). (B) Experimental design: position of hand and cursor for the conditions tested: (1) veridical, (2) vision displaced, (3) hand displaced. (C) Experimental setup. 
the elbow joint were sampled using a Flock of birds (FoB) (Ascension-Technology) magnetic six-degreeof-freedom (6-DOF) movement recording system. A single sensor was attached to the upper arm segment via an adjustable plastic cuff, while another sensor was fixed to the air sled where the forearm was fitted. The sensors were positioned approximately at the center of each arm segment.

\section{Data analysis}

The 3-D position of the hand point, and elbow were calculated from sensor position and orientation data. Then joint angle was calculated from these data. All kinematic data were low pass filtered at $12 \mathrm{~Hz}$ (3rd order, no-lag, dual pass Butterworth), and differentiated to yield velocity and acceleration values. Visual inspection was performed on every single trial to ensure that movement onset, peak acceleration, peak velocity, and movement termination were correctly determined.

We analyzed hand trajectories of the movements calculating the following measures of task performance: peak tangential velocity and acceleration, acceleration duration (defined as the elapsed time from movement start to time of peak velocity), movement duration (defined as the elapsed time from movement start to movement end), total distance traveled (calculated as the $2 \mathrm{D}$ distance between the start and the final location of the hand), and final position error (calculated as the distance between the hand point location at movement end and the center of the target). In order to assess the effect of changes of initial visual/proprioceptive information across the range of experimental manipulations on movement kinematics, we calculated the difference between the mean measures observed when the cursor or hand were in start position $90^{\circ}$ and $105^{\circ}(\mathrm{P} 90-\mathrm{P} 105)$ for movement distance, peak velocity and acceleration, and acceleration duration.

Means of the individual dependent measures of task performance were analyzed using repeatedmeasures $2($ Age $) \times 2$ (Target) $\times 4$ (Cursor position) $\times 4$ (Hand position) analyses of variance with one between-subject factor (Age: Younger and Older) and three within-subject factors (Target distance: Short and Long; Initial Cursor position: $90^{\circ}, 95^{\circ}, 100^{\circ}$, and $105^{\circ}$; and Initial Hand position: $90^{\circ}, 95^{\circ}, 100^{\circ}$, and $105^{\circ}$ ). For all analyses, statistical significance was tested using an alpha value of 0.05 and Tukey's HSD method was used for post-hoc analysis. We also conducted simple linear regression analysis for select sets of data using $\mathrm{JMP}^{\circledR}$ statistical software $\left(\mathrm{SAS}^{\circledR}\right)$. Comparison of correlation coefficients was done by converting individual $r$ values to $Z$ scores (Normalized $r$ ) using Fisher transformation.

\section{Results}

In this experiment, subjects performed targeted single-joint movements under sensory dissociation conditions imposed by a virtual reality environment, in which visual and proprioceptive information of initial limb position was dissociated prior to movement initiation. The conditions tested can be described as follows: "cursor displaced", indicated that the hand was in alignment with the start circle location but the visual display (cursor) indicated a false misalignment; whereas the "hand displaced", indicated that the hand was not aligned with the start circle location but the cursor indicated false alignment.

This study was designed to assess potential age-related differences in responding to sensory discrepancies about initial position to the control of movement distance. We analyzed these differences with repeated measures $2 \times 2 \times 4 \times 4$ analyses of variance with Age (young and older), Target distance (short and long), Cursor start location $\left(90^{\circ}, 95^{\circ}, 100^{\circ}\right.$, and $\left.105^{\circ}\right)$, and Hand start location $\left(90^{\circ}, 95^{\circ}, 100^{\circ}\right.$, and $105^{\circ}$ ) with Age as a between-subject factor and Target, Cursor and Hand as within subject factors.

Our ANOVA showed a main effect of age $(F(1,16)=16.03 ; P=0.0010)$, target distance $(F(1,16)=105.28 ; P<0.0001)$, cursor start location $(F(3,16)=21.70 ; P<0.0001)$, and hand start location $(F(3,16)=13.42 ; P<0.0001)$ on movement duration. Older participants took significant longer times to reach to the further target $(0.79 \pm 0.18 \mathrm{~s})$ than to the closer target $(0.77 \pm 0.18 \mathrm{~s})$, whereas the young participants produced had shorter times $(\mathrm{T} 0: 0.47 \pm 0.09 \mathrm{~s}, \mathrm{~T} 1$ : $0.52 \pm 0.10 \mathrm{~s}$ ) as compared to the older group. Similar effects were shown for acceleration duration, a main effect of age $(F(1,16)=13.67 ; P=0.0020)$, target distance $(F(1,16)=70.32 ; P<0.0001)$, cursor start location $(F(3,16)=12.89 ; P<0.0001)$, and hand start location $(F(3,16)=10.51 ; P<0.0001)$. As expected, older subjects $(0.30 \pm 0.08 \mathrm{~s})$ showed longer acceleration duration as compared to the younger $(0.17 \pm 0.07 \mathrm{~s})$.

Movement distance, final position error, peak velocity and peak acceleration showed main effects for target distance and cursor start location. The distance travelled toward $\mathrm{T} 0$ was significantly smaller $(0.17 \pm 0.07 \mathrm{~m})$ than the one toward $\mathrm{T} 1(0.20 \pm 0.06 \mathrm{~m})$ $(F(1,16)=755.56 ; P<0.0001)$. The changes in cursor start location had similar effect decreasing movement distance (C90: $0.20 \pm 0.06 \mathrm{~m}$; C95: $0.19 \pm 0.06 \mathrm{~m}$; C100: $0.18 \pm 0.07 \mathrm{~m}$; C105: $0.17 \pm 0.07 \mathrm{~m}$ ) 
$(F(3,16)=89.86 ; P<0.0001)$. Consequently final position errors increased with target distance (T0: $0.05 \pm 0.06 \mathrm{~m} ; \mathrm{T} 1: 0.06 \pm 0.05 \mathrm{~m})(F(1,16)=4.40$; $P=0.0364)$ and cursor start location $(F(3,16)=24.02$; $P<0.0001)$. Movements performed toward the further target reached a higher peak velocity $(0.71 \pm 0.31 \mathrm{~m} / \mathrm{s})$ than those toward the closer target $(0.63 \pm 0.26 \mathrm{~m} / \mathrm{s})$ $(F(1,16)=339.18 ; P<0.0001)$. Peak velocity also decreased as the cursor start location moved closer to the target (C90: $0.72 \pm 0.31 \mathrm{~m} / \mathrm{s} ; \mathrm{C} 95: 0.69 \pm 0.29 \mathrm{~m} / \mathrm{s}$; C100: $0.65 \pm 0.27 \mathrm{~m} / \mathrm{s} ; \mathrm{C} 105: 0.62 \pm 0.25 \mathrm{~m} / \mathrm{s}$ ) $(F(3,16)=89.86 ; P<0.0001)$. Moreover, peak acceleration $(F(1,16)=64.43 ; P<0.0001)$ was influenced by target distance and cursor start location $(F(3,16)=18.88 ; P<0.0001)$. Movements to the long target produced significantly higher peak acceleration $\left(7.61 \pm 5.23 \mathrm{~m} / \mathrm{s}^{2}\right)$ than those to the short target $\left(7.15 \pm 4.53 \mathrm{~m} / \mathrm{s}^{2}\right)$. Similarly, cursor start location produced greater peak acceleration for the further position as compared to those closer to the target (C90: $7.69 \pm 5.27 \mathrm{~m} / \mathrm{s}^{2} ; \mathrm{C} 95: 7.44 \pm 5.06 \mathrm{~m} / \mathrm{s}^{2}$; C100: $7.30 \pm 4.81 \mathrm{~m} / \mathrm{s}^{2} ; \mathrm{C} 105: 7.10 \pm 4.41 \mathrm{~m} / \mathrm{s}^{2}$ ).

In order to enhance the distinctive effect of cursor (C) or hand $(\mathrm{H})$ displacements on each group, we calculated the difference between the first initial position (i.e. $90^{\circ}$ ) and the forth initial position (i.e. $105^{\circ}$ ) in our dependent measures (movement distance, peak acceleration, acceleration duration and peak velocity) across the two targets, which are shown in the comparative plots of Figure 2 (this figure also depicts the quality of the ANOVA interactions mentioned above). Movement distance differences (Figure 2A) showed reverse effects on the two groups. Elderly subjects presented greater
A

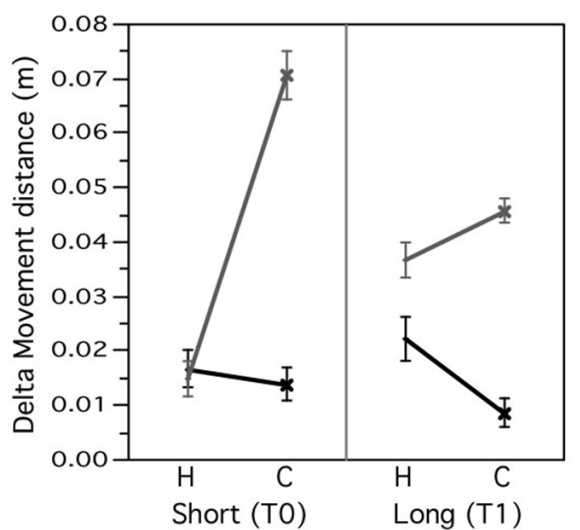

C

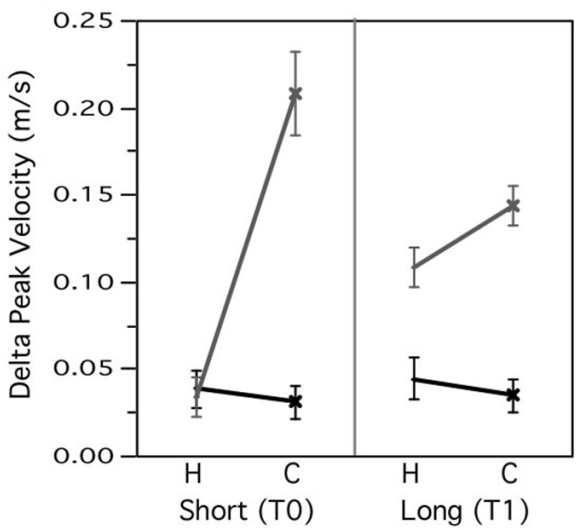

B

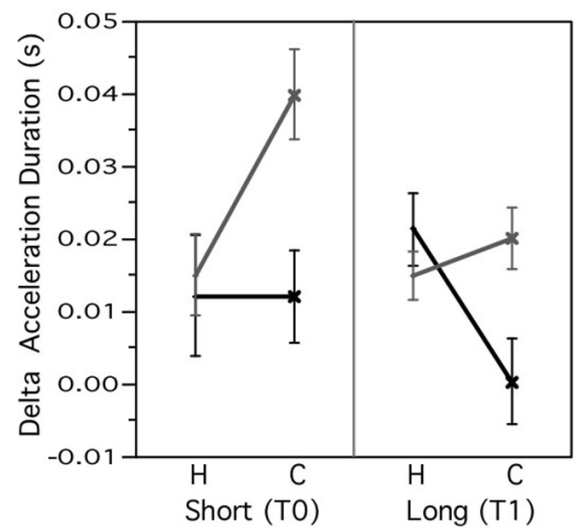

D

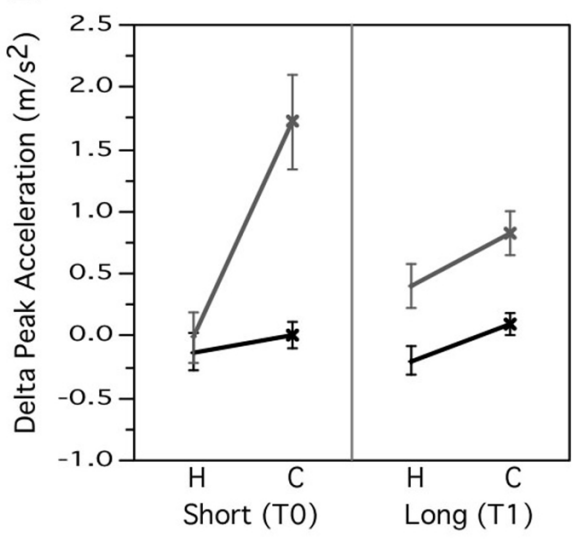

Group $\square$ Y $\square$

Figure 2. Displaced conditions. (A): Mean Delta Movement distance for each target is displayed for vision (Cursor) and proprioception (Hand) conditions of elderly and young subjects. (B): Mean Delta Acceleration duration. (C): Mean Delta Peak acceleration. (D): Mean Delta Peak velocity. Bars indicate SE. $(\mathrm{C})=$ cursor (vision). $(\mathrm{H})=$ hand (proprioception). Delta $=$ (Position 1 - Position 4) (position was cursor or hand on 1 of the 4 start locations). 
hand ( $\mathrm{H}$ - proprioception) reliance as compared to the younger subjects, which showed better reliance on cursor (C - vision). This difference was maximized on the elderly group when moving to the long target, whereas on the younger group this effect was minimized when performing longer movements. Similar effects were shown on the acceleration duration measurement (Figure 2B) and peak velocity (Figure 2C), with a slight variation on the peak acceleration measurement, where all subjects showed a decreased effect when moving toward the long target (Figure 2D).

\section{Distance and velocity analyses}

Movement distance was generally longer for the older participants as compared to the younger. This was confirmed by a 2 -way interaction between age and target $(F(1,16)=438.96 ; P<0.0001)$, such that the older participants travelled longer towards both targets (T0: $21 \pm 7 \mathrm{~cm} ; \mathrm{T} 1: 22 \pm 7 \mathrm{~cm}$ ) as compared to the young group (T0: $14 \pm 4 \mathrm{~cm}$; T1: $19 \pm 4 \mathrm{~cm}$ ). Consequently, we had the same 2-way interaction for movement error $(F(1,16)=19.67 ; P<0.0001)$. Young individuals showed similar errors for both targets $(5 \pm 3 \mathrm{~cm})$ in contrast with the older group who showed larger and significantly different errors for the two targets (T0: $6 \pm 5 \mathrm{~cm} ; \mathrm{T} 1: 8 \pm 6 \mathrm{~cm}$ ). Furthermore, final position movement errors substantially varied with cursor start location for the younger participants
$(F(1,16)=10.02 ; P<0.0001)$ but not for the elderly; however no significant differences with changes in hand initial location was found for both groups. An interaction between "Age and Cursor" $(F(3,16)=79.49$; $P<0.0001)$ presented interestingly effects; the young group better scaled their movement extent with cursor initial location, distinctively varied their movement extent for each cursor location, with no particular changes when the hand was moving. Conversely the older group showed no significant changes when hand or cursor location was displaced; i.e. movement extent was not scaled with the initial position manipulations. Table 2 summarizes the results for the total distance traveled across subjects group's, targets and the 4 initial positions for displaced conditions.

Older participants moved slower than the young. A two-way interaction between Age and Target $(F(1,16)=231.80 ; P<0.0001)$ revealed that the young (T0: $0.68 \pm 0.26 \mathrm{~m} / \mathrm{s} ; \mathrm{T} 1: 0.84 \pm 0.32 \mathrm{~m} / \mathrm{s}$ ) but not the older $(0.60 \pm 0.25 \mathrm{~m} / \mathrm{s})$ group significantly scaled their peak velocities according to the two targets. Additionally, this scaling of peak velocity significantly varied with cursor start locations (two-way interaction Age and Cursor: $F(3,16)=42.26 ; P<0.0001)$ for the young but not for the older, although no significant differences in either age groups were shown when initial hand position changed. Table 3 summarizes the results for peak tangential velocity across the

Table 2. Total distance traveled (Mean $\pm \mathrm{SE}$ ) across subjects' group $(\mathrm{E}=$ elder, $\mathrm{Y}=$ young), targets $(\mathrm{T} 0=$ short, $\mathrm{T} 1=$ long $)$ and the 4 initial positions for displaced conditions (Cursor (C90, C95, C100, C105) and Hand (F90, F95, F100, F105)).

\begin{tabular}{|c|c|c|c|c|c|}
\hline \multicolumn{2}{|c|}{ Cursor } & C90 & C95 & $\mathrm{C} 100$ & $\mathrm{C} 105$ \\
\hline \multirow{2}{*}{ T0 } & $\mathrm{E}$ & $0.212 \pm 0.011$ & $0.210 \pm 0.011$ & $0.205 \pm 0.011$ & $0.199 \pm 0.011$ \\
\hline & $\mathrm{Y}$ & $0.170 \pm 0.007$ & $0.149 \pm 0.006$ & $0.124 \pm 0.005$ & $0.099 \pm 0.005$ \\
\hline \multirow{2}{*}{$\mathrm{T} 1$} & E & $0.218 \pm 0.011$ & $0.215 \pm 0.011$ & $0.214 \pm 0.011$ & $0.209 \pm 0.011$ \\
\hline & Y & $0.213 \pm 0.008$ & $0.198 \pm 0.007$ & $0.184 \pm 0.007$ & $0.166 \pm 0.007$ \\
\hline \multicolumn{2}{|c|}{ Hand } & F90 & F95 & F100 & F105 \\
\hline \multirow{2}{*}{ T0 } & $\mathrm{E}$ & $0.215 \pm 0.012$ & $0.209 \pm 0.011$ & $0.204 \pm 0.011$ & $0.198 \pm 0.010$ \\
\hline & $\mathrm{Y}$ & $0.143 \pm 0.007$ & $0.139 \pm 0.008$ & $0.131 \pm 0.007$ & $0.129 \pm 0.007$ \\
\hline \multirow[b]{2}{*}{$\mathrm{T} 1$} & E & $0.225 \pm 0.012$ & $0.217 \pm 0.011$ & $0.210 \pm 0.011$ & $0.203 \pm 0.010$ \\
\hline & $\mathrm{Y}$ & $0.210 \pm 0.008$ & $0.196 \pm 0.007$ & $0.184 \pm 0.007$ & $0.173 \pm 0.008$ \\
\hline
\end{tabular}

Table 3. Peak tangential velocity (Mean $\pm \mathrm{SE})$ across subjects' group $(\mathrm{E}=$ elder, $\mathrm{Y}=$ young), targets $(\mathrm{T} 0=$ short, $\mathrm{T} 1=$ long $)$ and the 4 initial positions for displaced conditions (Cursor (C90, C95, C100, C105) and Hand (F90, F95, F100, F105)).

\begin{tabular}{|c|c|c|c|c|c|}
\hline \multicolumn{2}{|c|}{ Cursor } & C90 & $\mathrm{C} 95$ & $\mathrm{C} 100$ & C105 \\
\hline \multirow{2}{*}{ T0 } & $\mathrm{E}$ & $0.251 \pm 0.040$ & $0.250 \pm 0.040$ & $0.239 \pm 0.038$ & $0.237 \pm 0.038$ \\
\hline & Y & $0.299 \pm 0.053$ & $0.285 \pm 0.050$ & $0.237 \pm 0.042$ & $0.179 \pm 0.032$ \\
\hline \multirow{2}{*}{$\mathrm{T} 1$} & $\mathrm{E}$ & $0.276 \pm 0.044$ & $0.255 \pm 0.040$ & $0.246 \pm 0.039$ & $0.243 \pm 0.039$ \\
\hline & Y & $0.339 \pm 0.060$ & $0.316 \pm 0.056$ & $0.316 \pm 0.056$ & $0.302 \pm 0.053$ \\
\hline \multicolumn{2}{|c|}{ Hand } & F90 & F95 & F100 & F105 \\
\hline \multirow{2}{*}{ T0 } & $\mathrm{E}$ & $0.611 \pm 0.040$ & $0.602 \pm 0.041$ & $0.578 \pm 0.037$ & $0.573 \pm 0.037$ \\
\hline & Y & $0.702 \pm 0.046$ & $0.690 \pm 0.047$ & $0.665 \pm 0.045$ & $0.669 \pm 0.050$ \\
\hline \multirow{2}{*}{$\mathrm{T} 1$} & $\mathrm{E}$ & $0.628 \pm 0.043$ & $0.618 \pm 0.042$ & $0.594 \pm 0.039$ & $0.584 \pm 0.038$ \\
\hline & $\mathrm{Y}$ & $0.899 \pm 0.055$ & $0.845 \pm 0.056$ & $0.826 \pm 0.058$ & $0.791 \pm 0.058$ \\
\hline
\end{tabular}


subjects group's targets and the 4 initial positions for displaced conditions.

Figure $3 \mathrm{~A}$ shows movement distance plotted as a function of peak tangential velocity for both groups of representative subjects (older: left; young: right). As indicated by the figure, peak tangential velocity is a relatively strong predictor of distance for the younger adult $\left(\mathrm{r}^{2}=0.55(\mathrm{~T} 0), \mathrm{r}^{2}=0.62(\mathrm{~T} 1)\right)$ but not for the older adult $\left(r^{2}=0.12(\mathrm{~T} 0), r^{2}=0.19\right.$ (T1)). This finding was significant across all participants as indicated by Figure 3B showing a comparison of correlation coefficients across subjects. These values were normalized for statistical comparison, which indicated significant differences between the groups $(P<0.05)$.

\section{Acceleration analysis}

Acceleration amplitude and acceleration duration are two measures by which peak velocity can be scaled. In order to further explore the control mechanisms that might underlie the differences in visual and proprioceptive contributions to distance control in

\section{A}
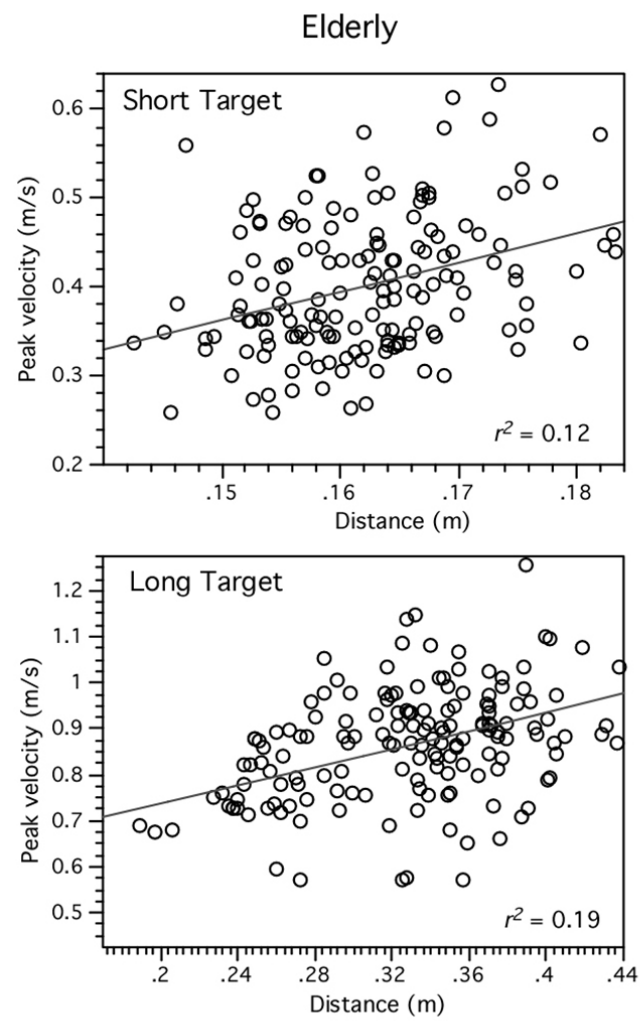

\section{B}

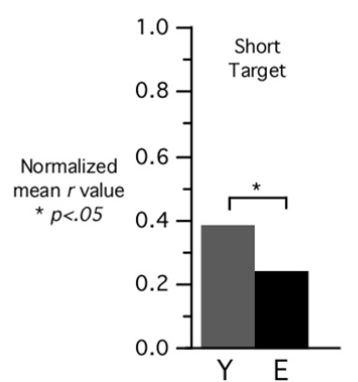

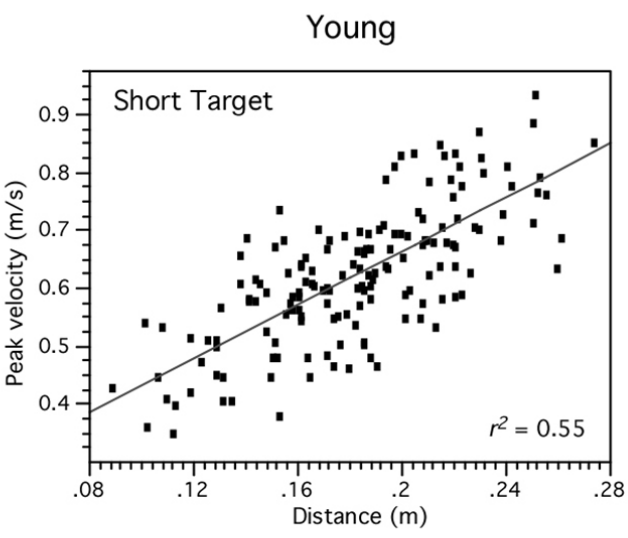
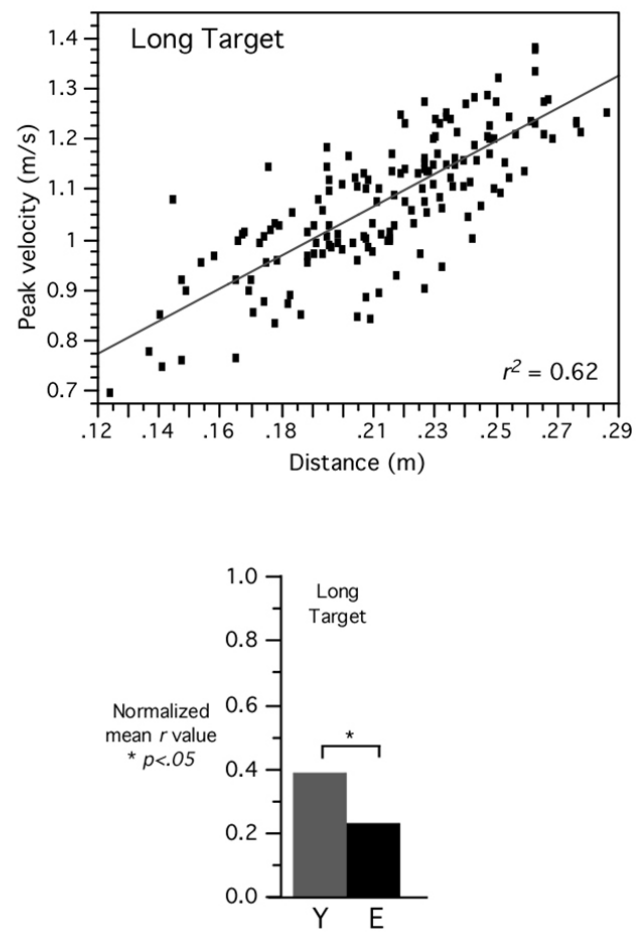

Figure 3. Displaced conditions. (A): Movement distance as predicted by peak tangential hand velocity of both groups for representative subjects of each group (short target (T0) and long target (T1)). (B): Normalized mean $r$ values for young (dark gray) and elderly (light gray) across subjects. ${ }^{*} P<0.05$ 
old and young adults, we further analyzed these two features of the acceleration profile. The results reveal an interaction between age and target for both measures, with the direction of interaction being different for each measure. Acceleration duration varied over groups and experimental conditions. Our ANOVA revealed an interaction between Age and Target $(F(1,16)=30.41 ; P<0.0001)$ such that young adults significantly increased their acceleration duration for the long target as compared to the short target (T0: $0.16 \pm 0.07 \mathrm{~s}, \mathrm{~T} 1: 0.19 \pm 0.06 \mathrm{~s})$, whereas the elderly group presented no significant changes between targets $(0.30 \pm 0.08 \mathrm{~s})$. Remarkably, this difference varied according to the cursor start location for the young adults (two-way interaction Age and Cursor: $F(3,16)=5.96 ; P=0.0005)$ but not for the older group. Target distance differently influenced peak acceleration for the two groups as movements performed by the young reached higher peaks than those performed by the old. Young subjects directly and substantially scaled their peaks for short and long targets (T0: $9.78 \pm 5.21 \mathrm{~m} / \mathrm{s}^{2}$, $\mathrm{T} 1: 10.83 \pm 5.98 \mathrm{~m} / \mathrm{s}^{2}$ ), whereas the older subjects did not $\left(5.05 \pm 2.35 \mathrm{~m} / \mathrm{s}^{2}\right)$ (two-way interaction Group and Target: $F(1,16)=71.59 ; P<0.0001)$. Also, the effect of cursor location was significant for the young as their acceleration amplitude decreased as the initial cursor position became closer to the target. A similar effect was not seen with older adults (two-way interaction Age and Cursor: $F(3,16)=18.18 ; P<0.0001)$. The results for acceleration peak and duration across subjects group's targets and the 4 initial positions for displaced conditions are summarized on Tables 4 and 5 .

As shown in Figure 4A, the amplitude of acceleration increased substantially for movements in which the cursor start position varied for a young adult whereas not for the older adult. Instead, the old participant increased the duration of acceleration with changes in cursor start location. This finding was significant across all young participants as indicated by Figure $4 \mathrm{C}$, showing significant $(P<0.01)$ scaling of peak acceleration with cursor (vision) condition. In contrast, the older adult showed extensive change in acceleration duration for movements in which the hand start position varied (Figure 4B), whereas the young subject showed minimal adjustment of acceleration amplitude. In fact, as shown by Figure $4 \mathrm{C}$, this scaling was presented across the older group $(P<0.05)$.

\section{Discussion}

The purpose of the study was to evaluate distinctive effects on reach kinematics for the two age groups (young and older adults) in responding to sensory discrepancies about initial hand position. We were thus mainly interested in assessing the response of

Table 4. Peak tangential acceleration (Mean \pm SE) across subjects' group $(\mathrm{E}=$ elder, $\mathrm{Y}=$ young), targets $(\mathrm{T} 0=\mathrm{short}, \mathrm{T} 1=\mathrm{long})$ and the 4 initial positions for displaced conditions (Cursor (C90, C95, C100, C105) and Hand (F90, F95, F100, F105)).

\begin{tabular}{|c|c|c|c|c|c|}
\hline \multicolumn{2}{|c|}{ Cursor } & C90 & C95 & $\mathrm{C} 100$ & C105 \\
\hline \multirow{2}{*}{$\mathrm{T} 0$} & $\mathrm{E}$ & $5.111 \pm 0.384$ & $4.920 \pm 0.345$ & $5.089 \pm 0.364$ & $5.105 \pm 0.376$ \\
\hline & $\mathrm{Y}$ & $10.599 \pm 1.048$ & $10.082 \pm 1.003$ & $9.552 \pm 0.898$ & $8.884 \pm 0.720$ \\
\hline \multirow[b]{2}{*}{$\mathrm{T} 1$} & $\mathrm{E}$ & $5.137 \pm 0.395$ & $4.976 \pm 0.355$ & $4.964 \pm 0.376$ & $5.037 \pm 0.391$ \\
\hline & $\mathrm{Y}$ & $11.196 \pm 1.106$ & $11.015 \pm 1.080$ & $10.748 \pm 1.068$ & $10.373 \pm 1.020$ \\
\hline \multicolumn{2}{|c|}{ Hand } & F90 & F95 & F100 & F105 \\
\hline \multirow{2}{*}{ T0 } & $\mathrm{E}$ & $5.023 \pm 0.327$ & $5.073 \pm 0.375$ & $4.980 \pm 0.355$ & $5.149 \pm 0.409$ \\
\hline & $\mathrm{Y}$ & $9.785 \pm 0.883$ & $9.768 \pm 0.923$ & $9.763 \pm 0.917$ & $9.800 \pm 1.004$ \\
\hline \multirow[b]{2}{*}{$\mathrm{T} 1$} & $\mathrm{E}$ & $4.890 \pm 0.348$ & $5.080 \pm 0.400$ & $5.053 \pm 0.380$ & $5.092 \pm 0.388$ \\
\hline & $\mathrm{Y}$ & $11.006 \pm 1.022$ & $10.814 \pm 1.072$ & $10.901 \pm 1.082$ & $10.610 \pm 1.103$ \\
\hline
\end{tabular}

Table 5. Acceleration duration (Mean $\pm \mathrm{SE}$ ) across subjects' group $(\mathrm{E}=$ elder, $\mathrm{Y}=$ young), targets $(\mathrm{T} 0=\mathrm{short}$, $\mathrm{T} 1=\mathrm{long})$ and the 4 initial positions for displaced conditions (Cursor (C90, C95, C100, C105) and Hand (F90, F95, F100, F105)).

\begin{tabular}{|c|c|c|c|c|c|}
\hline \multicolumn{2}{|c|}{ Cursor } & C90 & C95 & $\mathrm{C} 100$ & C105 \\
\hline \multirow{2}{*}{$\mathrm{T} 0$} & $\mathrm{E}$ & $0.301 \pm 0.012$ & $0.303 \pm 0.011$ & $0.297 \pm 0.013$ & $0.289 \pm 0.013$ \\
\hline & $\mathrm{Y}$ & $0.179 \pm 0.012$ & $0.165 \pm 0.011$ & $0.154 \pm 0.012$ & $0.139 \pm 0.012$ \\
\hline \multirow{2}{*}{$\mathrm{T} 1$} & $\mathrm{E}$ & $0.301 \pm 0.011$ & $0.303 \pm 0.011$ & $0.309 \pm 0.014$ & $0.301 \pm 0.013$ \\
\hline & $\mathrm{Y}$ & $0.199 \pm 0.011$ & $0.192 \pm 0.011$ & $0.187 \pm 0.011$ & $0.179 \pm 0.012$ \\
\hline \multicolumn{2}{|c|}{ Hand } & F90 & F95 & F100 & F105 \\
\hline \multirow{2}{*}{$\mathrm{T} 0$} & $\mathrm{E}$ & $0.302 \pm 0.011$ & $0.301 \pm 0.013$ & $0.297 \pm 0.013$ & $0.290 \pm 0.013$ \\
\hline & $\mathrm{Y}$ & $0.168 \pm 0.011$ & $0.162 \pm 0.011$ & $0.155 \pm 0.012$ & $0.153 \pm 0.012$ \\
\hline \multirow{2}{*}{$\mathrm{T} 1$} & $\mathrm{E}$ & $0.320 \pm 0.013$ & $0.298 \pm 0.011$ & $0.297 \pm 0.012$ & $0.299 \pm 0.014$ \\
\hline & $\mathrm{Y}$ & $0.197 \pm 0.011$ & $0.194 \pm 0.012$ & $0.184 \pm 0.011$ & $0.182 \pm 0.012$ \\
\hline
\end{tabular}


A
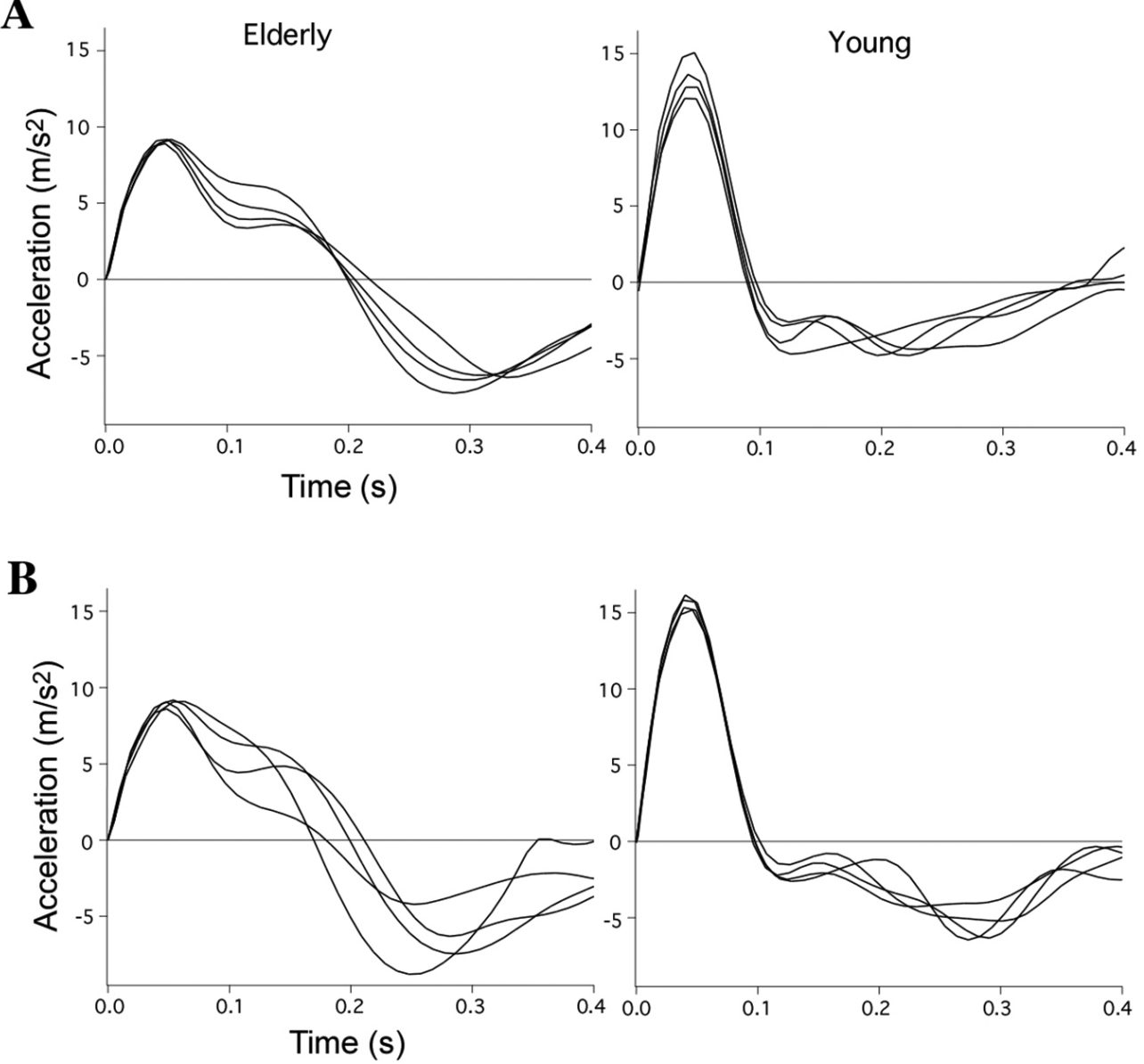

C
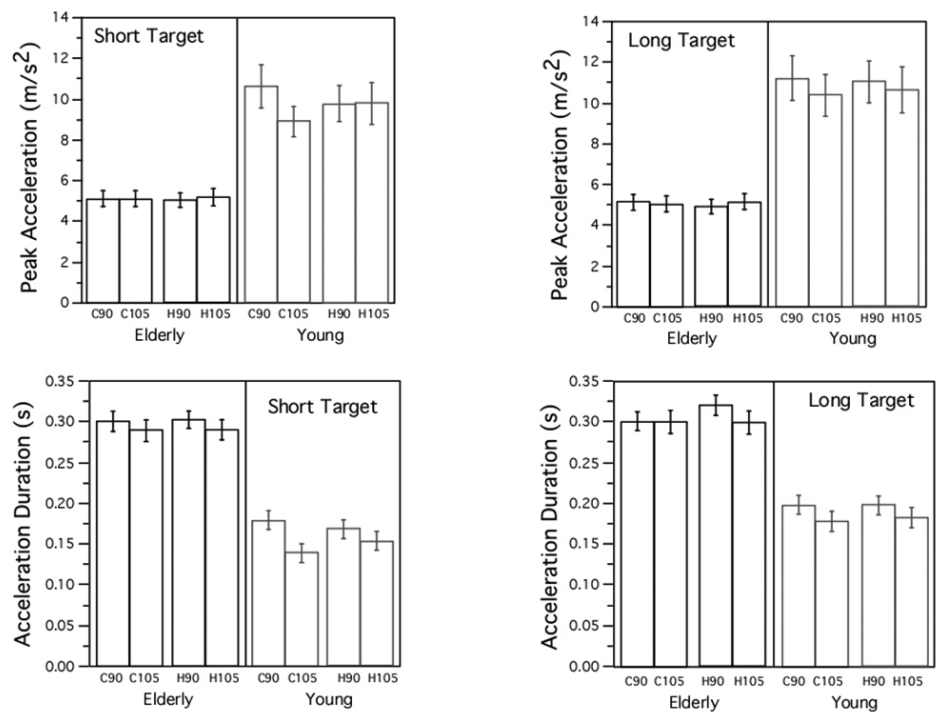

Figure 4. Displaced conditions. (A): Acceleration profiles for movements from the 4 cursor (vision) start locations towards the short target for representative subjects. (B): Acceleration profiles for movements from the 4 hand (proprioception) start locations towards the short target for representative subjects. (C) Average peak acceleration and acceleration duration as a function of cursor $(\mathrm{C})$ and hand $(\mathrm{H})$ initial position $\left(\mathrm{P} 90=90^{\circ}\right.$ and $\left.\mathrm{P} 105=105^{\circ}\right)$ for the short $(\mathrm{T} 0)$ and long $(\mathrm{T} 1)$ targets. Error bars represent between subjects standard errors . 
each group when false alignment between visual information about hand start location and actual hand position were presented.

The effects of initial position information on the two experimental groups were very distinctive; suggesting mechanistic differences in how each group effectively scaled acceleration features with initial vision and proprioception information dissociation. The young group movements were well characterized by movement distance and peak tangential acceleration mainly defined by visually derived cursor information; whereas for the older group the manipulation of initial position information produced greater responses on the time course (acceleration duration) variables by proprioceptive information about actual hand location. These two features of the acceleration profile have been well studied and are thought to reflect independent control mechanisms (Brown and Cooke, 1981, 1984, 1990; Cooke and Brown, 1990; Ghez, 1979; Mutha and Sainburg, 2007; Schaefer and Sainburg, 2008). Acceleration amplitude occurs early in movement and reflects largely pre-planned mechanisms, whereas, acceleration duration is substantially affected by sensory feedback; reflecting corrective mechanisms associated with distance control adjustments. Our analysis of acceleration amplitude and duration suggests that the two groups differently planned movement distance: older adults utilized sensory feedback mechanisms to adjust the duration of the initial acceleration impulse so as to specify movement speed in accord with changes in alteration of hand initial position (proprioception information). In contrast, the young adults specified distance primarily by adjusting the amplitude of the initial acceleration phase in agreement with the alterations presented in initial cursor locations (visual information).

The idea that older adults' utilization of feedbackmediated error-correction mechanisms to a greater degree has previously been proposed, although the possible explanations of age-related differences in control mechanisms have yielded different results. Elderly subjects showed higher levels of EMG activity and coactivation as well as decreases in performance, in terms of velocity and error rate (Darling et al., 1989; Seidler and Stelmach, 1996). Potential reasons of age-related differences in performance and muscle activity may be suggestive, e.g. differences in muscle strength, muscle fiber composition, motor skill, sensory feedback, and increased reaction time (Warabi et al., 1986; Seidler and Stelmach, 1996). The requirement for precision are largest during the deceleration phase when approaching the target; this phase is prolonged while maximum speed remains unchanged during voluntary movements in the older adult resulting generally in longer movement time, as well as submovements, which are frequent in the older participants (Cooke et al., 1989; Darling et al., 1989; Pohl et al., 1996; Pratt et al., 1994). These changes may be due to deteriorated motor control, but may also indicate a strategic difference between the two groups, whereby the elderly use "safer" strategies to avoid errors that result in slower speeds compared to the young. In addition, aging is associated with significant changes in the neuromuscular reflex system properties and perceptual processing deficits, which are mainly associated with weaker and slower muscle force generation and with a certain level of difficulty, but not with significant decrease in motoneuronal excitability (Chung et al., 2005; Head et al., 2008).

For the young subjects, peak acceleration decreased with start location and was accompanied by a significant decrease in acceleration duration, further supporting the notion that the young rely on feedforward mechanism and preprogram a greater portion of the movement. The older participants, in contrast, substantially decreased their acceleration duration but not their peak acceleration, suggesting effective reliance on feedback mechanism. Thus for a given aiming task, the young required only a small correction, while the elderly had to make a large corrective set of commands in order to achieve the target; performing a greater portion of the movement under feedback control as opposed pre-planned programming control.

According to previous studies, older individuals were not disrupted to a greater extent than the young when visual feedback was removed prior to movement start (Seidler-Dobrin and Stelmach, 1998). It was suggested that in the absence of vision the subjects used proprioceptive information to guide their movements, however as proprioceptive information was not as accurate as visual feedback, this would explain the increase in amplitude and duration of the movements. Serrien et al. (1996) found that the absence or presence of visual feedback influenced the performance of the young subjects more than that of the elderly, the young subjects performed more stable movements under normal circumstances but were more strongly affected by vibratory stimuli during the performance of movements. They suggested that this manipulation could be related to a reduced sensory sensitivity as a function of aging, and hypothesize that the continuous updating between the proprioceptive and visual maps introduces an imprecision in the calibration process, eliciting additional variability into the system. In the present study participants had no visual feedback during movements, and when conflicting information about the initial location was presented older adults 
better adapted their movements in accordance with proprioceptive information, suggesting that aging deficits are relate to visual information.

The effects of the false alignment between visual information and actual hand position were different for the two age groups. Previous studies have shown conflicting findings when visual distortion was presented. Some showed comparable performance in young and old subjects (Bock and Schneider 2002; Buch et al., 2003; Etnier and Landers, 1998; Roller et al., 2002), but other showed distinct degradation in the elderly (Buch et al., 2003; Bock, 2005; Fernandez-Ruiz et al., 2000; McNay and Willingham, 1998). This discrepancy has been related to deficits of strategic control in elderly and has been interpreted as evidence that recalibration is ageresistant whereas strategic control might deteriorate in old age (Fernandez-Ruiz et al., 2000; McNay and Willingham, 1998). In another set of studies, Chaput and Proteau (1996a, 1996b) suggested that older individuals appeared to process independently from each other depending on the different sources of sensory information available (vision and/or proprioception). Moreover, when the temporal constraints of the task were stringent, older adults seemed to rely more on modes of control in which sensory information plays a minimal role when compared to younger subjects. Also, when multiple targets were used, older adults appeared to program a response which was optimally suited for a "central" target. Our findings are in accordance with the view that age-related changes are most likely because of impaired strategic control.

The young and older participants in this study presented different strategies according to the sensory information accessible to perform the movements. The young were able to completely rely on visual information through feedforward mechanism, implying that peak acceleration served as a reasonable predictor of movement distance. On the other hand, older adults showed a greater reliance on feedback mechanisms, with acceleration duration being a good predictor of distance and causing them to be slower with increased movement duration.

The effects of sensory discrepancies were clearly different for our two age groups, with elderly subjects relying on proprioceptive information, and younger subjects relying more on visual information. However, it should be stressed that our current findings do not indicate whether proprioception is more accurately used in either group. Rather, that the elderly tend to rely more on proprioception than on vision for controlling reaching movements. Our current findings appear to both support and extend previous work by Seidler et al. (2002), which showed that the movements of elderly subjects were less accurate than younger subjects, when movements were made with visual feedback. However, when performed without visual feedback, both groups showed similar accuracies, emphasizing the tendency for younger, but not older subjects, to employ visual feedback to increase the accuracy of their movements. The current results indicate a strong tendency for older subjects to rely more extensively than younger subjects on proprioception in controlling movement distance.

\section{Acknowledgements}

This work was supported by a FAPESP/Brazil grant (05/00161-8). Thanks to Robert L. Sainburg for providing the data acquisition software and Lais Fajersztajn for assistance with recruiting the participants and with data collection.

\section{References}

Allison LK, Kiemel T, Jeka JJ. Multisensory reweighting of vision and touch is intact in healthy and fall-prone older adults. Experimental Brain Research. 2006; 175:342-52. PMid:16858599. http://dx.doi.org/10.1007/s00221-0060559-7

Bagesteiro LB, Sarlegna FR, Sainburg RL. Differential influence of vision and proprioception on control of movement distance. Experimental Brain Research. 2006; 171(3):35870. PMid:16307242. http://dx.doi.org/10.1007/s00221005-0272-y

Bagesteiro LB and Sainburg RL. Interlimb transfer of load compensation during rapid elbow joint movements. Experimental Brain Research. 2005; 161:155-65. PMid:15551087. http://dx.doi.org/10.1007/s00221-0042055-2

Bock O. Components of sensorimotor adaptation in young and elderly subjects. Experimental Brain Research. 2005;160:259-63.

Bock O, Schneider S. Sensorimotor adaptation in young and elderly humans. Neuroscience \& Biobehavioral Reviews. 2002; 26:761-7. http://dx.doi.org/10.1016/S01497634(02)00063-5

Brown SH, Cooke JD. Amplitude- and instruction-dependent modulation of movement-related electromyogram activity in humans. Journal of Physiology. 1981; 316:97-107. PMid:7320884 PMCid:PMC1248138.

Brown SH, Cooke JD. Initial agonist burst duration depends on movement amplitude. Experimental Brain Research. 1984; 55(3):523-7. PMid:6468556. http://dx.doi. org/10.1007/BF00235283

Brown SH, Cooke JD. Movement-related phasic muscle activation. I. Relations with temporal profile of movement. Journal of Neurophysiology. 1990; 63(3):455-64. PMid:2329355. 
Brumagne S, Cordo P, Verschueren S. Proprioceptive weighting changes in persons with low back pain and elderly persons during upright standing. Neuroscience Letters. 2004; 366(1):63-6. PMid:15265591. http://dx.doi. org/10.1016/j.neulet.2004.05.013

Buch ER, Young S, Contreras-Vidal JL. Visuomotor Adaptation in Normal Aging. Learning \& Memory. 2003;10:55-63. http:// dx.doi.org/10.1101/lm.50303

Chaput S, Proteau L. Aging and motor control. Journals of Gerontology Series B: Psychological Sciences and Social Sciences. 1996a; 51:346-55. http://dx.doi.org/10.1093/ geronb/51B.6.P346

Chaput S, Proteau L. Modifications with aging in the role played by vision and proprioception for movement control. Experimental Aging Research. 1996b; 22(1):1-21. http:// dx.doi.org/10.1080/03610739608253994

Chung SG, Van Rey EM, Bai Z, Rogers MW, Roth EJ, Zhang LQ. Aging-related neuromuscular changes characterized by tendon reflex system properties. Archives of Physical Medicine and Rehabilitation. 2005; 86(2):318-27. PMid:15706561. http://dx.doi.org/10.1016/j.apmr.2004.04.048

Cole KJ. Grasp force control in older adults. Journal of Motor Behavior. 1991; 23(4):251-8. PMid:14766507. http:// dx.doi.org/10.1080/00222895.1991.9942036

Cooke JD, Brown SH. Movement-related phasic muscle activation. II. Generation and functional role of the triphasic pattern. Journal of Neurophysiology. 1990; 63(3):465-72. PMid:2329356.

Cooke JD, Brown SH, Cunningham DA. Kinematics of arm movements in elderly humans. Neurobiology of Aging. 1989; 10(2):159-65. http://dx.doi.org/10.1016/01974580(89)90025-0

Darling WG, Cooke JD, Brown SH. Control of simple arm movements in elderly humans. Neurobiology of Aging. 1989; 10(2):149-57. http://dx.doi.org/10.1016/01974580(89)90024-9

Dean JC, Alexander NB, Kuo AD. The effect of lateral stabilization on walking in young and old adults. IEEE Transactions on Biomedical Engineering. 2007; 54(11):191926. PMid: 18018687 . http://dx.doi.org/10.1109/ TBME.2007.901031

Dietz V, Colombo G. Influence of body load on the gait pattern in Parkinson's disease. Movement Disorders. 1998; 13(2):25561. PMid:9539338. http://dx.doi.org/10.1002/mds.870130210

Dijkerman HC, de Haan EH. Somatosensory processes subserving perception and action. Behavioral and Brain Sciences. 2007; 30:189-201. PMid:17705910. http://dx.doi. org/10.1017/S0140525X07001392

Etnier JL, Landers DM. Motor performance and motor learning as a function of age and fitness. Research Quarterly for Exercise \& Sport. 1998; 69:136-46. http://dx.doi.org/1 $0.1080 / 02701367.1998 .10607679$

Falconer J, Hughes SL, Naughton BJ, Singer R, Chang RW, Sinacore JM. Self report and performance-based hand function tests as correlates of dependency in the elderly.
Journal of the American Geriatrics Society. 1991; 39(7):695-9. PMid:2061536.

Fernandez-Ruiz J, Hall C, Vergara P, Diaz R. Prism adaptation in normal aging: slower adaptation rate and larger after effect. Cognitive Brain Research. 2000; 9:223-6. http:// dx.doi.org/10.1016/S0926-6410(99)00057-9

Ghez C. Contributions of central programs to rapid limb movement in the cat. In: Asanuma H, Wilson VJ, editors. Integration in the Nervous System. Tokyo: Igaku-Shoin; 1979. p. $305-19$.

Goggin NL, Meeuwsen HJ. Age-related differences in the control of spatial aiming movements. Research Quarterly for Exercise \& Sport. 1992; 63(4):366-72. http://dx.doi.or g/10.1080/02701367.1992.10608758

Haaland KY, Harrington DL, Grice JW. Effects of aging on planning and implementing arm movements. Psychology and Aging. 1993; 8(4):617-32.

Head D, Rodrigue KM, Kennedy KM, Raz N. Neuroanatomical and Cognitive Mediators of Age-Related Differences in Episodic Memory. Neuropsychology. 2008; 22(4):491-507.

Ketcham CJ, Dounskaia NV, Stelmach GE. Age-related differences in the control of multijoint movements. Motor Control. 2004; 8(4):422-36.

Ketcham CJ, Seidler RD, Van Gemmert AW, Stelmach GE. Age-related kinematic differences as influenced by task difficulty, target size, and movement amplitude. Journals of Gerontology Series B: Psychological Sciences and Social Sciences. 2002; 57:54-64. http://dx.doi.org/10.1093/ geronb/57.1.P54

Lanza IR, Towse TF, Caldwell GE, Wigmore DM, KentBraun JA. Effects of age on human muscle torque, velocity, and power in two muscle groups. Journal of Applied Physiology. 2003; 95(6):2361-9. PMid:12923120.

Larsson L, Grimby G, Karlsson J. Muscle strength and speed of movement in relation to age and muscle morphology. Journal of Applied Physiology. 1979; 46(3):451-6. PMid:438011.

Light KE and Spirduso WW. Effects of adult aging on the movement complexity factor of response programming. Journal of Gerontology. 1990; 45:107-9. http://dx.doi. org/10.1093/geronj/45.3.P107

Lyons J, Elliott D, Swanson LR, Chua R. The use of vision in manual aiming by young and older adults. Journal of Aging and Physical Activity. 1996; 4:165-78.

McNay EC, Willingham DB. Deficit in learning of a motor skill requiring strategy, but not of perceptualmotor recalibration, with aging. Learning \& Memory. 1998; 4:41120. http://dx.doi.org/10.1101/1m.4.5.411

Mutha PK, Sainburg RL. Control of velocity and position in single joint movements. Human Movement Science. 2007; 26(6):808-23. PMid:17931729 PMCid:PMC2607068. http://dx.doi.org/10.1016/j. humov.2007.06.001

Oldfield RC. The assessment and analysis of handedness: the Edinburgh Inventory. Neuropsychologia. 1971; 9:97-113. http://dx.doi.org/10.1016/0028-3932(71)90067-4 
Peterka RJ, Loughlin PJ. Dynamic regulation of sensorimotor integration in human postural control. Journal of Neurophysiology. 2004; 91(1):410-23. PMid:13679407. http://dx.doi.org/10.1152/jn.00516.2003

Pohl PS, Winstein CJ, Fisher BE. The locus of age-related movement slowing: sensory processing in continuous goal-directed aiming. Journals of Gerontology Series B: Psychological Sciences and Social Sciences. 1996; 51(2):94102. http://dx.doi.org/10.1093/geronb/51B.2.P94

Pratt J, Chasteen AL, Abrams RA. Rapid aimed limb movements: age differences and practice effects in component submovements. Psychology and Aging. 1994; 9(2):325-34. PMid:8054180. http://dx.doi.org/10.1037/0882-7974.9.2.325

Raz N, Rodrigue KM, Haacke EM. Brain aging and its modifiers: insights from in vivo neuromorphometry and susceptibility weighted imaging. Annals of the New York Academy of Sciences. 2007; 1097:84-93. Review. PMid:17413014 PMCid:PMC2630248. http://dx.doi. org/10.1196/annals.1379.018

Raz N and Rodrigue KM. Differential aging of the brain: patterns, cognitive correlates and modifiers. Neuroscience \& Biobehavioral Reviews. 2006; 30(6):730-48. Review. PMid:16919333. http://dx.doi.org/10.1016/j. neubiorev.2006.07.001

Raz N, Lindenberger U, Rodrigue KM, Kennedy KM, Head D, Williamson A, Dahle C, Gerstorf D, Acker JD.; Regional brain changes in aging healthy adults: general trends, individual differences and modifiers. Cerebral Cortex. 2005; 15(11):1676-89. PMid:15703252. http:// dx.doi.org/10.1093/cercor/bhi044

Rivner MH, Swift TR, Malik K. Influence of age and height on nerve conduction. Muscle \& Nerve. 2001; 24(9):1134 41. PMid:11494265. http://dx.doi.org/10.1002/mus.1124

Roller CA, Cohen HS, Kimball KT, Bloomberg JJ. Effects of normal aging on visuomotor plasticity. Neurobiology of Aging. 2002; 23:117-23. http://dx.doi.org/10.1016/S01974580(01)00264-0

Sainburg RL, Lateiner JE, Latash ML, Bagesteiro LB. Effects of altering initial position on movement direction and extent. Journal of Neurophysiology. 2003; 89(1):401-15. PMid:12522189. http://dx.doi.org/10.1152/jn.00243.2002

Salthouse TA. Aging and measures of processing speed. Biological Psychology. 2000; 54:35-54. http://dx.doi. org/10.1016/S0301-0511(00)00052-1

Sarlegna FR. Impairment of online control of reaching movements with aging: a double-step study. Neuroscience Letters. 2006; 403(3):309-14. PMid:16723186. http://dx.doi. org/10.1016/j.neulet.2006.05.003

Schaefer SY, Sainburg RL. Sequential processes for controlling distance in multijoint movements. Journal of Motor Behavior. 2008; 40(4):325-36. http://dx.doi. org/10.3200/JMBR.40.4.325-336

Schultz AB, Alexander NB, Ashton-Miller JA. Biomechanical analyses of rising from a chair. Journal of Biomechanics. 1992; 25(12):1383-91. http://dx.doi. org/10.1016/0021-9290(92)90052-3
Seidler RD, Alberts JL, Stelmach GE. Changes in multi-joint performance with age. Motor Control. 2002; 6(1):19-31.

Seidler RD, Stelmach GE. EMG Patterns: age differences in a speed- constrained, self-initiated task. Society for Neuroscience - Abstract. 1996; 22:1638.

Seidler-Dobrin RD, Stelmach GE. Persistence in visual feedback control by the elderly. Experimental Brain Research. 1998; 119(4):467-74. http://dx.doi.org/10.1007/ s002210050362

Serrien DJ, Teasdale N, Bard C, Fleury M. Age-related differences in the integration of sensory information during the execution of a bimanual coordination task. Journal of Motor Behavior. 1996; 28(4):337-47. PMid:14769555. http:// dx.doi.org/10.1080/00222895.1996.10544603

Skinner HB, Barrack RL, Cook SD. Age-related decline in proprioception. Clinical Orthopaedics and Related Research. 1984; 184:208-11. PMid:6705349.

Sober SJ, Sabes PN. Multisensory integration during motor planning. Journal of Neuroscience. 2003; 23:6982-92. PMid:12904459.

Sober SJ, Sabes PN. Flexible strategies for sensory integration during motor planning. Nature Neuroscience. 2005; 8:490-7. PMid:15793578 PMCid:PMC2538489.

Speers RA, Kuo AD, Horak FB. Contributions of altered sensation and feedback responses to changes in coordination of postural control due to aging. Gait \& Posture. 2002; 16:2030. http://dx.doi.org/10.1016/S0966-6362(02)00003-6

Teasdale N, Stelmach GE, Breunig A, Meeuwsen HJ. Age differences in visual sensory integration. Experimental Brain Research. 1991; 85(3):691-6. http://dx.doi.org/10.1007/ BF00231755

Van Hedel HJ, Dietz V. The influence of age on learning a locomotor task. Clinical Neurophysiology. 2004; 115(9):213443. PMid:15294216. http://dx.doi.org/10.1016/j. clinph.2004.03.029

Verdu E, Ceballos D, Vilches JJ, Navarro X. Influence of aging on peripheral nerve function and regeneration. Journal of the Peripheral Nervous System. 2000; 5(4):191208. PMid:11151980. http://dx.doi.org/10.1046/j.15298027.2000.00026.x

Verhaeghen P, Cerella J, Basak C. Aging, task complexity, and efficiency modes: the influence of working memory involvement on age differences in response times for verbal and visuospatial tasks. Neuropsychology, Development, and Cognition. Section B, Aging, Neuropsychology and Cognition. 2006; 13(2):254-80. PMid:16807201. http:// dx.doi.org/10.1080/138255890969267

Warabi T, Noda H, Kato T. Effect of aging on sensorimotor functions of eye and hand movements. Experimental Neurology. 1986; 92(3):686-97. http://dx.doi. org/10.1016/0014-4886(86)90309-2

Westlake KP and Culham EG. Sensory-specific balance training in older adults: effect on proprioceptive reintegration and cognitive demands. Physical Therapy. 2007; 87(10):127483. PMid:17636154. http://dx.doi.org/10.2522/ptj.20060263 
Woollacott MH, Shumway-Cook A, Nashner LM. Aging and posture control: changes in sensory organization and muscular coordination. International Journal of Aging and Human Development. 1986; 23(2):97-114. PMid:3557634. http://dx.doi.org/10.2190/VXN3-N3RT-54JB-X16X
Yan JH, Thomas JR, Stelmach GE, Thomas KT. Developmental features of rapid aiming arm movements across the lifespan. Journal of Motor Behavior. 2000; 32:121-40. PMid:11005944. http://dx.doi. org/10.1080/00222890009601365

\section{Author}

